\title{
The Bronchitis Randomized On NAC Cost-Utility Study (BRONCUS): hypothesis and design
}

\author{
M. Decramer*, P.N.R. Dekhuijzen", T. Troosters*, C. van Herwaarden", M. Rutten-van Mölken ${ }^{*}$, \\ C.P.O. van Schayck ${ }^{+}$, D. Olivieri ${ }^{\S}$, I. Lankhorst ${ }^{f}$, A. Ardia $^{f}$ and the BRONCUS-trial Committee
}

\begin{abstract}
The Bronchitis Randomized On NAC Cost-Utility Study (BRONCUS): hypothesis and design. M. Decramer, P.N.R. Dekhuijzen, T. Troosters, C.van Herwaarden, M. Rutten-van Mölken, C.P.O.van Schayck, D. Olivieri, I. Lankhorst, A. Ardia, and the BRONCUS-trial Committee. (C) ERS Journals Ltd 2001.

ABSTRACT: Chronic obstructive pulmonary disease (COPD) is an irreversible disorder characterized by airflow obstruction and a progressive decline in forced expiratory volume in one second (FEV1). At present, no treatment except quitting smoking appears to affect the progression of the disease. Oxidative stress has been implicated in its pathogenesis.

The Bronchitis Randomized on NAC Cost-Utility Study (BRONCUS) is a phase III, randomized, double-blind, placebo-controlled, parallel group, multicentre study designed to assess the effectiveness of the antioxidant agent $\mathrm{N}$-acetylcysteine (NAC) in altering the decline in FEV1, exacerbation rate, and quality of life in patients with moderate to severe COPD. In addition, cost-utility of the treatment will be estimated. Patients will be followed for 3 yrs and evaluated every 3 months. The necessary sample size to demonstrate an effect on the decline in FEV1 of $20 \mathrm{~mL} \cdot \mathrm{yr}^{-1}$ was estimated to be 478 patients.

Five hundred and twenty-three patients with moderate to severe COPD were recruited from 10 European countries from June 1, 1997-December 31, 1999. They were $63 \pm 8$ yrs old and consisted of $243(46 \%)$ current smokers and $280(54 \%)$ exsmokers. Patients had on the average $4.9 \pm 1.6$ exacerbations during the last 2 yrs. Postbronchodilator FEV1 averaged $5 \overline{7} \pm 9 \%$ and the reversibility after $400 \mu \mathrm{g}$ of Salbutamol averaged $4 \pm 4 \%$ predicted.

The final results of the trial will be available in about 2 yrs. The study will provide objective data on the effects of $\mathrm{N}$-acetylcysteine on outcome variables in chronic obstructive pulmonary disease.

Eur Respir J 2001; 17: 329-336.
\end{abstract}

\begin{abstract}
*Respiratory Division, University Hospital, Katholieke Universiteit Leuven, B3000 Leuven, Belgium, ${ }^{\#}$ Dept of Pulmonary Diseases, University Medical Centre Nijmegen, the Netherlands, "Institute for Medical Technology Assessment, Erasmus University Rotterdam, the Netherlands, ${ }^{+}$Institute for Extra and Transmural Health Care, Universiteit Maastricht, the Netherlands, ${ }^{8}$ Respiratory Division, Ospedale Rasori Parma, Italy and ${ }^{\prime}$ Zambon Group Bresso-Milano, Italy.
\end{abstract}

Correspondence: M. Decramer, Professor of Medicine, University Hospital, Respiratory Division, Herestraat 49, B3000 Leuven, Belgium Fax: 3216346803

Keywords: COPD

cost-utility

decline in FEV

$\mathrm{N}$-acetylcysteine

oxidative stress

quality of life

Received: June 292000

Accepted after revision November 20 2000
Chronic obstructive pulmonary disease (COPD) is a poorly reversible chronic disease characterized by slowly progressive airflow obstruction [1]. There is accumulating evidence that the basic mechanism involved in this disease is a chronic inflammation present in the airways, distinct from the chronic inflammation present in asthma [2]. Indeed, the cells involved are predominantly CD-8 T-lymphocytes, in contrast to CD-4 T-lymphocytes in asthma. In asthma, eosinophilic granulocytes are involved, whereas in COPD, mainly neutrophilic granulocytes and macrophages are present. The cytokines and mediators involved in the inflammation are also different $[3,4]$. Finally, the inflammation in asthma is largely steroidsensitive, while it is steroid-resistant in COPD patients $[3,4]$. Accordingly, asthma usually responds well to inhaled corticosteroid therapy, whereas the effects of inhaled corticosteroids are relatively disappointing in COPD patients [5-7].

At present, the only treatment that has been shown to slow COPD progression is smoking cessation [8]. Consequently, active smoking cessation programmes will always be the first step in the treatment of COPD. There is no unequivocal evidence indicating that systemic corticosteroids affect the progression of COPD [9, 10]. Inhaled corticosteroids cause a small improvement in forced expiratory volume in one second (FEV1), but in general, do not affect the decline in FEV1, thought to be the most direct measure of the progression of COPD [5-7]. For fluticasone, however, a reduction in the rate of deterioration in health status and the exacerbation rate was demonstrated [7].

It has often been claimed that treatment with Nacetylcysteine (NAC) has beneficial effects in COPD patients, although few randomised studies are presently available on the effects of NAC on outcome variables in COPD patients. A number of controlled trials conducted on a large series of patients provided evidence for a reduction in symptoms, in the duration and rate of exacerbations $[11,12]$ and in the number of sick days [13]. However, this has not been found in all studies [14]. In a recent meta-analysis, GRANDJEAN et al. [15] collected 6 double-blind, randomised, controlled studies on NAC in COPD, with exacerbation rate as a primary 
outcome variable. Although some inhomogeneity of the effect appeared to be present, as a whole, a $23 \%$ reduction of the exacerbation frequency was found. The duration of the treatment in these trials, however, was limited to 6 months. Similar results were recently obtained by STEY et al. [16]; in a meta-analysis of eleven studies with treatment periods of $12-24$ weeks, NAC appeared to reduce exacerbation rate and symptoms.

Potential beneficial effects were originally claimed to result from a reduction in mucus viscosity and improvement of mucociliary clearance, leading to reduced mucus retention. Research during the last decade, however, pointed to another potential mechanism of action of NAC in COPD. Indeed, oxidant radicals, whether generated from exogenous sources such as inspiration of polluted air and cigarette smoke, or produced by activated neutrophils or macrophages, may cause damage to the lung matrix $[17,18]$. This damage may be caused directly or through interference with elastin synthesis and repair. Oxidative stress also initiates an inflammatory response, leading to sequestration of neutrophils into the lungs. Their degranulation causes further connective tissue destruction. In addition, NAC penetrates into the cells, where it is deacetylated to L-cysteine, thus supporting the biosynthesis of glutathione (GSH), which is one of the most important antioxidant systems in the cell, playing a key role in the cellular protective mechanisms. Clear evidence for enhanced oxidative stress in COPD patients is presently available, although the relationship between oxidative stress and the development of irreversible and progressive airflow obstruction is less well documented [17]. Whether potential beneficial effects of NAC in COPD relate to its antioxidant action is not yet defined.

In order to provide a more comprehensive answer to the question of whether NAC affects outcome variables in COPD patients, the Bronchitis Randomised On NAC Cost-Utility Study (BRONCUS) was designed by a panel of international experts. The hypothesis and design of the study are reported in the present manuscript.

The hypothesis tested in the trial is that NAC can reduce the annual decline in FEV1 in COPD patients and, in addition, that it can reduce exacerbation rate. The trial will also investigate the effect of NAC on quality of life and on pharmacoeconomic measures through a cost-utility analysis. The primary endpoints of the study are the decline in FEV1 and the reduction in exacerbation rate. The secondary endpoints are quality of life and cost-utility.

\section{Materials and methods}

\section{Study design}

The general design of the study is a phase III, twoarm double-blind, randomised placebo-controlled, parallel group trial, in which patients either receive usual care for COPD plus placebo or usual care plus NAC $600 \mathrm{mg}$ per day. NAC is given in one administration taken at the same time every day. Patients are followed for $3 \mathrm{yrs}$ and the following endpoints are

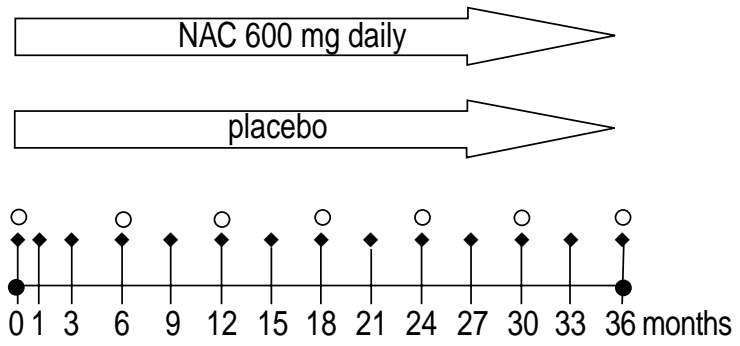

Fig. 1. - Study flowchart. $\downarrow$ : indicates pulmonary function test was performed; $\bigcirc$ : indicates Quality of Life questionnaire was completed. NAC: N-acetylcysteine.

considered: 1) decline in FEV1 and; 2) exacerbation rate, as primary outcome variables; 3) quality of life and; 4) cost-utility, as secondary outcome variables. The general design of the study is schematically shown in the flowchart in figure 1. Patients were stratified according to the use of inhaled corticosteroids.

Patients were first seen at a screening visit where inclusion/exclusion criteria, medical and medication history, smoking history, smoking habits, number of exacerbations per year during the previous $2 \mathrm{yrs}$, physical examination, lung function tests including functional residual capacity and diffusing capacity, chest radiograph, electrocardiography (ECG), laboratory tests, pregnancy test, the St. George's Respiratory Questionnaire and the EuroQoL were recorded. If complying with the inclusion criteria, the patient was asked to sign the informed consent form, randomly allocated to one of the treatment groups and asked to take the study medication for the following $3 \mathrm{yrs}$. Patients were advised to quit smoking prior to the trial. Only nonsmokers or patients who did not alter their smoking habits, were included. Exsmokers were defined as patients who stopped smoking for $\geqslant 6$ months. Smoking habits were only verified by history.

After the start of the study, patients returned to the investigational centre at months 1,3 and then every 3 months. At each visit the following variables were recorded: physical examination, lung function, pregnancy test, smoking habits, concomitant medication, spontaneous adverse events, patient diary card and compliance. During exacerbations, diary cards were filled in daily. At months 6, 12, 18, 24, 30 and 36 the St.George's Respiratory Questionnaire and the EuroQoL were filled out and at months 12, 24 and 36 laboratory tests were carried out (fig. 1). For each exacerbation, a monitoring form was completed that contained questions about healthcare resource use and absence from work or other daily activities.

\section{Patients}

Number of patients. The inclusion of patients which started on June 1, 1997 was completed on December 31, 1999. A total of 523 patients were included in the trial. These patients were recruited in 54 different centres in 10 European countries. The last patient will finish the study on December 31, 2002 and a few months later the authors will probably be able to provide answers to the hypotheses formulated in the 
present trial. So far, with a median follow-up of 688 days (range 224-1095), 112 patients (21\%) have dropped out of the study.

Sample size determination. The sample size for the study was calculated based on a power analysis. This analysis was based on the assumptions that a) the annual decline in FEV1 was $20 \mathrm{~mL}$ in normal subjects and $60 \mathrm{~mL}$ in COPD patients, b) that NAC would reduce the annual decline in FEV1 from $60 \mathrm{~mL} \cdot \mathrm{yr}^{-1}$ to $40 \mathrm{~mL} \cdot \mathrm{yr}^{-1}$ and c) that the SD of the annual decline in FEV1 was $55 \mathrm{~mL} \cdot \mathrm{yr}^{-1}$. The latter assumption was based on preliminary data indicating that the SD decreased as the number of yearly measurements of FEV1 increased [19]. The decision was made that it would not be possible to extend the trial past 3 yrs duration. In addition, great care was taken to reduce the variability in FEV1 measurement as much as possible. Reversibility was performed at each visit and only postbronchodilator FEV1 will be used as an outcome variable. If a patient presented with an exacerbation, they were rescheduled 6 weeks later. It was assumed that $35 \%$ of the patients would be lost during the 3 yrs treatment, leading to a reduction of the overall treatment effect to $14.5 \mathrm{~mL} \cdot \mathrm{yr}^{-1}$ instead of $20 \mathrm{~mL} \cdot \mathrm{yr}^{-1}$. Following this assumption, 227 patients were required per treatment arm or 454 patients in total, for a power of $80 \%$. Finally, it was assumed that $5 \%$ of the patients would be lost before being evaluable, which was defined as having $\geqslant 3$ FEV1 measurements over six months. This further increased the number of patients required to 239 per treatment arm or 478 in total.

The number of patients required for a significant effect on exacerbation rate and quality of life is well below the number required for an effect on the decline in FEV1. The 523 patients presently enrolled are likely to meet the study's goals in terms of number of patients required. It should be noted that this number of patients may be adequate for the potential overall effects of the trial, but power may be insufficient if smaller treatment effects are observed or if subgroup analyses (i.e. smokers versus non-smokers) are considered.

Inclusion criteria. The following inclusion criteria were used in the study: 1) smoking-related COPD; 2) aged between 40 and $70 \mathrm{yrs}$; 3) any race or sex, females with childbearing potential were required to use an acceptable method for birth control and have a negative pregnancy test; 4) history of $\geqslant 2$ exacerbations per yr during 2 yrs previous to the enrollment date; 5) post-bronchodilator FEV1 40-70\% of predicted; 6) FEV1 reversibility $<12 \%$ of the predicted value, $15 \mathrm{~min}$ after $400 \mu \mathrm{g}$ (4 puffs) of Salbutamol (Ventolin $\mathbb{R}$, GlaxoSmithKline, Stockley Park, UK) by metered dose inhaler (MDI) and spacer; 7) FEV1 vital capacity (VC) $<88 \%$ of the predicted value in males, or $<89 \%$ of the predicted value in females $(>1.64$ residual sDs below predicted value); 8) smokers or exsmokers; 9) able to communicate meaningfully with the study personnel and to understand and read fluently in the native language; 10) written informed consent.
Exclusion criteria. The following exclusion criteria were used: 1) known history of intolerance for NAC; 2) not allowed medication; inhaled corticosteroids were allowed, but it was recommended to patients to use the same dose throughout the entire study period; they were further recommended to use antitussive agents, bronchodilators, mucolytic agents other than NAC and theophylline, if necessary; concomitant medication was recorded in the case report form (CRF); patients were advised not to use vitamins or other dietary supplements; 3) continuous treatment with oral corticosteroids; 4) long-term treatment with NAC for $\geqslant 3$ months; 5) history of asthma, allergic rhinitis, and/or allergic eczema; 6) long-term oxygen therapy or expected to attend an oxygen therapy programme within the next 3 yrs. 7) $\alpha 1$-antitrypsin deficiency; 8) cystic fibrosis; 9) bronchiectasis; 10) history of infection or active infection due to Mycobacterium tuberculosis (except for patients with minimal old T-lesions); 11) pneumoconiosis; 12) pulmonary restriction due to any other pulmonary disease, apart from the one concerned with the study population; 13) history of active peptic ulcer or intestinal malabsorption; 14) congestive heart failure class 2 or more of the New York Heart Association (NYHA); 15) reduced life expectancy due to other disease (e.g. malignancies); 16) evidence of illicit drug use or abuse of alcohol; 17) planned for lung transplantation at the time of admission to the study or expected to be transplanted within $3 \mathrm{yrs;} 18$ ) enrolled in rehabilitation programs, within the next 3 yrs as far as can be estimated by a chest physician; 19) participating in another trial within 3 months prior to the beginning of the study; 20) no compliance in taking medications;

Baseline characteristics. Baseline characteristics are summarized in table 1 . On average, patients had moderate to severe COPD with a postbronchodilator FEV1 of $57 \pm 9 \%$ predicted. Moreover, they had limited reversibility after Salbutamol $400 \mu \mathrm{g}(4 \pm 48 \%$

Table 1.-Baseline characteristics of the patients

Characteristic

Male/Female

Age yrs

Current/exsmokers

Inhaled steroids

Duration of the disease

Number of exacerbations last 2 yrs

Postbronchodilator FEV1 L

Postbronchodilator FEV1 \% pred

FEV1 reversibility \% pred

EuroQol: patient valuation $(\mathrm{n}=404)$

SGRQ: total $(n=418)$

SGRQ: symptoms $(\mathrm{n}=448)$

SGRQ: activity $(\mathrm{n}=418)$

SGRQ: impact $(\mathrm{n}=418)$

$413(78 \%) / 110(22 \%)$ $63 \pm 8$

$243(46 \%) / 280(54 \%)$

$365(70 \%)$

$9 \pm 7$

$4.9 \pm 1.6$

$1.64 \pm 0.38$

$57 \pm 9$

$4 \pm 4$

$63 \pm 15$

$40 \pm 15$

$52 \pm 17$

$50 \pm 20$

$30 \pm 17$

The number for EuroQol and SGRQ refers to the number of questionnaires with a valid score. Data are presented as mean $\pm \mathrm{SD}$ or number $(\%)$. FEV1: forced expiratory volume in one second; SGRQ: St. George's Respiratory Questionnaire. 
pred). They were $63 \pm 8$ yrs old, 413 were male $(78 \%)$ and $110(22 \%)$ female. They had COPD for $9 \pm 7$ yrs and had $4.9 \pm 1.6$ exacerbations during the last 2 yrs. Two hundred and forty-three (46\%) were current smokers and $280(54 \%)$ were exsmokers. Three hundred and sixty-five patients $(70 \%)$ were treated with inhaled corticosteroids. No differences in baseline characteristics were observed between countries.

\section{Outcome measures}

Clinical assessment. The investigator took a medical history and performed a clinical examination at each visit.

Spirometry. As the decline in FEV1 was the primary endpoint of the study, special attention was given to the methodology of spirometry. It was performed according to the European Respiratory Society (ERS) standards [20]. Spirometry was done with the subject in the seated position, wearing a nose clip. The best of $\geqslant 3$ technically satisfactory attempts was chosen. The largest and the second largest attempt, could not differ by more than $5 \%$ or $100 \mathrm{~mL}$, whichever was greatest.

At each visit, FEV1 and slow vital capacity (VC) were measured. All measurements were performed before and $15 \mathrm{~min}$ after the administration of $400 \mu \mathrm{g}$ Salbutamol (Ventolin, Glaxo) by MDI with a spacer. Measurements were always made at the same time of the day, between 8 and 11 am. Patients were asked to refrain from smoking and not to ingest caffeine for $\geqslant 2 \mathrm{~h}$ prior to the test [21]. They were always performed with the same equipment and by the same technician. The FEV1/VC ratio was calculated using VC obtained during a slow VC manoeuvre.

All measurements were performed with the same equipment in a particular centre. The equipment consisted, in essence, of a pneumotachograph, with volume being obtained from integration of the flow signal. Wet or dry spirometers and mass flow sensors were not allowed. The minimal detectable volume of the device was less than $25 \mathrm{~mL}$. Spirometers were excluded because they were not routinely used anymore in most investigational centres. A spirometer was not used for the study as the authors did not want to use equipment that was inferior to that available in the pulmonary function laboratories involved in the study. Calibration was performed with a $3 \mathrm{~L}$ syringe daily at different flow rates $\left(6 \mathrm{~L} \cdot \mathrm{s}^{-1}, 3 \mathrm{~L} \cdot \mathrm{s}^{-1}\right.$ and $\left.1 \mathrm{~L} \cdot \mathrm{s}^{-1}\right)$. All spirograms and calibration data were kept in the patient file and held available to the Quality Control Committee (QCC).

Reversibility testing was performed according to the following instructions: 1) shake the pressurized MDI (Ventolin $\mathbb{R}, 100 \mu \mathrm{g})$; 2) connect the MDI to the Volumatic; 3) fire one puff; 4) let the patient immediately inhale five times with tidal breathing; 5) repeat steps 3 and 4 three more times. Reversibility was expressed as percentage of predicted FEV1 using the following formula:
post-Salbutamol FEV1 - pre-Salbutamol FEV1 Predicted FEV1

$\times 100$

At the screening visit and at the end of the study, diffusing capacity of carbon monoxide (TL,CO) and functional residual capacity (FRC) were measured with the equipment available in the laboratory after acceptance by the QCC. The tests were performed according to ERS guidelines [20]. Thoracic gas volume (TGV) or FRC was measured by whole body plethysmography or by a dilution method. TL,CO was preferably measured by means of the single breath method using carbon monoxide. At the end of the study, these measurements were performed on the same device as at the screening visit.

The correct performance of all spirometric procedures was supervised by the QCC. At the beginning of the study, each centre had to submit spirograms to the QCC before patients were entered in the study. After following this procedure correctly for three patients, the centre was allowed to include patients without prior agreement of the QCC. At that time and for these centres, QCC further monitored spirograms by performing random sample analysis of spirograms. This was possible as all spirograms were kept in the file of the patients.

Quality of life. Two quality of life instruments were used in the present trial: a disease-specific instrument and a generic instrument. The disease-specific instrument was the St. George's Respiratory Questionnaire (SGRQ) [22]. This questionnaire contains 76 questions divided into three domains: symptoms, activity and impacts. The scores are aggregated in an overall score and a score for each of the domains. The scores are calculated using weights attached to each question. The weights were found to be similar across countries and languages [23]. A domain score is created by summing the weights for all positive responses and expressing it as a percentage of the sum of the weights for all items in that domain. Scores range from 0 (indicating no impairment) to 100 (indicating maximum impairment). The minimal clinically relevant change in scores is 4 points. Translations of the St. George's Respiratory Questionnaire were available for all countries participating in the study; Belgium, Estonia, France, Spain, Italy, the Netherlands, Germany, Poland, Portugal, and Sweden. Completing the questionnaire takes on average $25 \mathrm{~min}$. The generic instrument used was a utility instrument; the EuroQoL [24]. The EuroQoL consists of 2 sections: a descriptive section and a valuation section. The descriptive section contains 5 dimensions: mobility, self-care, usual activities, pain/discomfort, and anxiety/depression. Each dimension is divided into three levels of functioning (level one being the best and level three being the worst). Patients were first asked to describe their health by ticking off one level of functioning for each of the 5 dimensions. Second, in the valuation section, the patients are asked to value their health status on a rating scale. The rating scale is a vertical 
visual analogue scale ranging from 0 (worst possible health state) to 100 (best possible health state). It takes about 5-10 min to complete the EuroQoL. Besides patients' valuations, British general public valuations are available for the EuroQoL health states [25]. These general public valuations will be applied to the health states as described by the COPD patients in this trial.

Both questionnaires were administered every 6 months during the control visits. In order to standardize the conditions the following procedure was followed. The questionnaire was completed in a separate room in the clinic, before the patient was examined by the investigator. A trial nurse gave the patients instructions on to how to fill out the questionnaire. The nurse, however, did not interpret the questionnaire for the patient and she left the room while the patient was filling out the questionnaire.

Exacerbations. Since exacerbations were an important endpoint in the present study, great care was taken in defining exacerbations. An exacerbation was defined as "increased dyspnoea and/or cough associated with a change in quality and quantity of sputum, which led the patient to seek medical attention and lasting for $\geqslant 3$ days". The same definition was used for exacerbations occurring before and during the trial. The duration of the exacerbation was defined as the duration of the medical intervention. The patient was instructed to call the investigator at the onset of the exacerbation. The duration thus lasted from the first telephone call until the end of medical treatment. The duration of hospitalization was from the day of admission until the day of discharge. Exacerbations requiring hospitalizations were defined as "severe", while those not requiring hospitalization were considered "not severe". Exacerbations were managed with appropriate care as judged by the Investigator. No standard treatment packages were made available to the participants. Diary cards were analysed for the presence of increases in symptoms. No peak expiratory flow (PEF) measurements were performed during exacerbations.

Cost-utility analysis. The economic evaluation study was conducted from a societal perspective. This implied that all relevant costs were included, regardless of whether they were made within or outside the healthcare sector, and regardless of whether they were borne by government, private or public insurers, or the patients and their families. The time-horizon of the economic evaluation was 3 yrs. Three categories of costs were calculated: direct medical costs, direct nonmedical costs and productivity costs. Direct medical costs were defined as the costs associated with healthcare utilization. This included the following types of resource use: number of hospital admissions, length of hospital stay, unscheduled laboratory tests and lung function tests, imaging procedures, bronchoscopy, pulmonary scintigraphy, pulmonary angiography, number of emergency room visits, number of unscheduled contacts with the investigator, number of contacts with other specialists, number of contacts with general practitioners, number of outpatient contacts with a nurse, concomitant medication, and number of transportations by ambulance. Direct nonmedical costs were defined as the nonmedical costs directly related to the disease or the treatment. These consisted of travel costs associated with unscheduled physician or hospital visits, costs of paid help and costs of unpaid help. Productivity costs were defined as the costs associated with reduced productivity due to absence from work and days of inactivity. Here the number of days of absence from paid work and number of days unable to perform usual daily activities were recorded.

For each COPD exacerbation, this resource use was recorded on an exacerbation monitoring form in the CRF. Hence, only COPD related resource use was included in the calculations. The resource use was converted into costs by multiplying with unit costs, which were collected separately from the trial. These unit costs were partly based on country-specific costaccounting studies and partly on the charges as reimbursed by the social insurance, assuming that these charges reflect average costs. Production losses were valued using the friction cost approach [26]. This approach is based on the idea that the amount of production lost due to disease depends on the time-span organizations need to restore the initial production level. It is assumed that sick employees can be replaced after a period necessary for adaptation (the friction period). In the friction cost approach, productivity costs are calculated by multiplying the days absent from paid work with the gross daily wage, where the number of days absent from work is limited to the duration of the friction period (e.g. in the Netherlands, the friction period is currently about 4 months).

When neither one of the treatment strategies is dominant (i.e. more effective and less costly) the following incremental cost-effectiveness ratios were calculated: 1) Costs per exacerbation avoided. 2) Costs per additional patient reaching 4 points improvement in SGRQ total score. 3) Costs per quality adjusted life year gained.

\section{Discussion}

The design of the present study is directed at critically examining the effects of NAC treatment on outcome variables in COPD patients in a phase III, randomised, double-blind, placebo-controlled, parallel group design. The primary outcome variables considered were the annual decline in FEV1 and exacerbations and the secondary outcome variables considered were quality of life and cost-utility.

The patients aimed for in the present trial were those with moderate to severe COPD. This was apparently achieved with an average postbronchodilator FEV1 of $57 \%$ pred. The clinical diagnosis of COPD was confirmed by the poor reversibility after Salbutamol $(4 \pm 4 \%$ pred). Fifty-four percent of the patients were exsmokers and $46 \%$ were current smokers. On the average they had 4.9 exacerbations in the 2 yrs preceding the trial. As a whole this population is clearly different from the population studied in the The 
European Respiratory Society's Study on Chronic Obstructive Pulmonary Disease (EUROSCOP) [5] and Copenhagen City Lung Study [6], in which patients with incipient COPD coming from the general population were studied. The population used in the present study closely matches the population studied in the Inhaled Steroids in Obstructive Lung Disease (ISOLDE) trial, from the point of view of FEV1, reversibility and smoking habits [7]. The present patients, however, clearly exhibited higher exacerbation rates than the patients in the ISOLDE trial (2.45 versus exacerbations $\left.\cdot \mathrm{yr}^{-1}\right)$. This was not surprising, since in the present study, patients were selected to have $\geqslant 2$ exacerbations $\cdot \mathrm{yr}^{-1}$, at the entry.

The number of patients enrolled in the present study exceeded the number of patients required to obtain the necessary statistical power. The sample calculation was based on the presumptive effect on FEV1-decline as this is the most critical variable. Several assumptions, however, underlie the sample size calculation. The most significant of those are the assumption of a treatment effect of $20 \mathrm{~mL} \cdot \mathrm{yr}^{-1}$, an SD of the decline of $55 \mathrm{~mL} \cdot \mathrm{yr}^{-1}$, a drop-out of $5 \%$ before 6 months, and a drop-out of $35 \%$ of the patients before 3 yrs. The assumption of a treatment effect of $20 \mathrm{~mL} \cdot \mathrm{yr}^{-1}$ appears reasonable in view of the results obtained in the large trials with inhaled corticosteroids. Indeed, the treatment effect of inhaled corticosteroids in the ISOLDE trial was $64 \mathrm{~mL}$ over 3 yrs [7] and in the EUROSCOP trial it was $40 \mathrm{~mL}$ over 3 yrs [5]. In the three published trials on inhaled corticosteroids, the power analysis was also based on a treatment effect of $20 \mathrm{~mL} \cdot \mathrm{yr}^{-1}$ [5-7].

The assumption of an SD of the annual decline of $55 \mathrm{~mL} \cdot \mathrm{yr}^{-1}$ may be more subject to controversy. Indeed, in the EUROSCOP trial [5], the SD of the decline in FEV1 was assumed to be $100 \mathrm{~mL} \cdot \mathrm{yr}^{-1}$ as a pretrial assumption and it was effectively considerably larger in a large population study [27]. In the Lung Health Study [8], however, it was $58 \mathrm{~mL} \cdot \mathrm{yr}^{-1}$, while it was $75 \mathrm{~mL} \cdot \mathrm{yr}^{-1}$ in the ISOLDE trial [7]. It should be stressed however, that in the present study, great care was taken to reduce variability of the FEV1 measurement. Indeed, patients were always tested on the same equipment by the same technician, at the same time of the day and the equipment was frequently calibrated. Measurements were always performed after administration of bronchodilator and only postbronchodilator FEV1 is being considered. Clear spirometry guidelines were distributed to the investigators and adherence to the guidelines was verified by the QCC. Finally, in a pilot study in 120 patients, the SD of the annual decline was found to be $50 \mathrm{~mL}$, provided $\geqslant 12$ measurements were performed over 3 yrs (unpublished data). Similar observations were made in a large study in general practice [19]. In the present study, 12 measurements were performed in all patients. Measurement every 3 months was shown to be optimal in a longitudinal study in patients with emphysema and normal subjects [28]. In view of the variability of the annual decline observed in other studies [5-8], it appears that the estimate of the decline in FEV1 used in the power analysis for the present study may be relatively optimistic. Nevertheless, it is felt that a number of variables were controlled such as diurnal variation and avoiding the performance of spirometry during exacerbations, which were not controlled in previous studies [5-8].

Exacerbations are an important end-point of the study as well, and great care was taken to define them. Recently, however, SEemungal et al. [29] demonstrated that up to $50 \%$ of exacerbations were not reported by patients. In the present study, attention is primarily directed towards the reported ones, unreported ones may be recovered from the analysis of the diary cards. SEEMUNGal et al's study [29] also demonstrated that exacerbations clearly reduce PEF in COPD patients. PEF recovered afterwards with recovery being complete in $75 \%$ of the exacerbations after 35 days [29]. In the present study, spirometry was postponed for 6 weeks if an exacerbation was present. This interval appears appropriate as by that time the effects on spirometry have disappeared in the large majority of the patients.

The assumptions made about drop-out in the present trial appear entirely reasonable. Indeed, at the time of analysis the drop-out amounted to 112 patients or $21 \%$, for a median follow-up of 688 days. Provided that the drop-out rate would remain constant over the course of the study, this would yield a drop-out rate of $34 \%$ calculated over the 3 yrs of the study. Several studies, however, clearly demonstrated that the drop-out rate in long-term studies is likely to be considerably greater in the first year of the study [19]. Taking this observation into account, the present drop-out appears to fall well short of the assumptions made at the onset of the study. Evidently, the reasons for drop-out will be analysed with the final analysis.

In conclusion, the hypothesis and design of a phase III, double-blind, randomised, placebo-controlled, parallel group multicentre study, investigating the effects of treatment with $\mathrm{N}$-acetylcysteine on annual decline in forced expiratory volume in one second, exacerbation rate, quality of life and cost-utility, in patients with moderate to severe chronic obstructive pulmonary disease, have been reported. In total, 523 patients were included. This is well above the number of patients necessary to have enough statistical power to test the overall treatment effect, even considering a drop-out rate which is clearly above the one observed so far. The trial will be finished by December 31, 2002, when the last patient included will have a follow-up of 3 yrs.

\section{Appendix: Trial organization}

The study was performed through the actions of the BRONCUS-trial committee, the Steering Committee, Quality Control Committee, Country Coordinators and the participating centres.

\section{BRONCUS-trial committee}

M. Decramer (Chairman), A. Ardia, W. De Backer, P. N. R. Dekhuijzen, M. Del Dono, R. Jägi, J. F. Muir, D. Nowak, A. Nusch, D. Olivieri, R. Pellegrino, G. Riise, M. Rutten-van Mölken, V. Sobradillo, T. Troosters, C. van Herwaarden, C. P. Van Schayck. 


\section{Steering committee}

The development of the protocol and all relevant decisions related to the trial were taken by the Steering committee. This committee consisted of the following members: M. Decramer (Leuven, Belgium) (Chairman), A. Ardia (Zambon, Italy), D. Olivieri (Parma, Italy), M. Rutten-van Mölken (Rotterdam, the Netherlands), T. Troosters (Leuven, Belgium), C. van Herwaarden (Nijmegen, the Netherlands), C. P. van Schayck (Maastricht, the Netherlands). The committee decided by consensus.

\section{Quality control committee}

To ensure the quality of the spirometric data a Quality Control Committee (QCC) was installed. It consisted of R. Pellegrino (Cuneo, Italy) (Chairman), J. Festen (Nijmegen, the Netherlands), and A. Ardia (Zambon, Italy). The strategy followed by the QCC consisted of a validation of the centres at the beginning of the trial and examination of random samples of spirograms during the trial. Regular feedback was sent to the investigators on the most relevant problems encountered with spirometry in this trial. Frequent meetings of the investigators with the country coordinators further assured strict adherence to the spirometry guidelines.

\section{Country coordinators}

In each country, one investigator acted as a country coordinator. His main mission was to transmit the instructions of the Steering Committee to the investigators in his country. Conversely, he also brought problems arising in his country to the attention of the Steering Committee prompting adjustments or further specifications to the protocol. The country coordinators consisted of the following group: R. Avila (Lisboa, Portugal), W. De Backer (Antwerp, Belgium), P. N. R. Dekhuijzen (Nijmegen, the Netherlands), M. Del Donno (Parma, Italy), R. Jägi (Tartu, Estonia), J. F. Muir (Rouen, France), D. Nowak (Lodz, Poland), A. Nusch (Essen, Germany), G. Riise (Gothenburg, Sweden), and V. Sobradillo (Bilbao, Spain).

\section{Participating centres}

The following investigators participated in the study: M. Decramer (Leuven, Belgium), W. De Backer (Antwerp, Belgium), P. M. Mengeot (Montignies sur Sambre, Belgium), J. Verhaert (Lanaken, Belgium), B. De Wispelaere (Turnhout, Belgium), L. Delaunois (Mont-Godinne, Belgium), R. J. Broux (Liège, Belgium), J. Bruart (La Louvière, Belgium), A. Nusch (Essen, Germany), H. Reichert (Essen, Germany), H. Steffen (Landsberg am Lech, Germany), B. Kromer (Augsburg, Germany), D. Rost (Augsburg, Germany), V. Sobradillo (Bilbao, Spain), R. Rodriguez-Roisin (Barcelona, Spain), H. Vera Hernando (La Coruna, Spain), J. L. Viejo Banuelos (Burgos, Spain), J. Martinez Gonzalez del Rio (Oviedo, Spain), N. Gonzalez-Mangado (Madrid, Spain), J. M. Rodriguez Gonzalez-Moro (Madrid, Spain), J. Castillo Gomez
(Sevilla, Spain), T. Veidebaum (Tallinn, Estonia), E. Leesik (Tartu, Estonia), J. F. Muir (Rouen, France), B. Blaive (Nice, France), P. Guerin (Lyon, France), P. Camus (Dijon, France), E. Weitzemblum (Strasbourg, France), J. C. Pujet (Paris, France), M. Del Donno (Parma, Italy), M. Luisetti (Pavia, Italy), L. Pesce (Padova, Italy), C. Sanguinetti (Osimo-An, Italy), T. Todisco (Perugia, Italy), A. J. Neve (Sittard, the Netherlands), D. S. Postma (Groningen, the Netherlands), A. M. P. Greefhorst (Hengelo, the Netherlands), H. M. M. Pouwels (Venlo, the Netherlands), H. E. J. Sinninghe Damste (Amsterdam, the Netherlands), A. J. M. Schreurs (Amsterdam, the Netherlands), P. N. R. Dekhuijzen (Nijmegen, the Netherlands), J. A. van Noord (Heerlen, the Netherlands), F. J. J. van den Elshout (Arnhem, the Netherlands), C. A. R. Groot (Oss, the Netherlands), V. D. Graaf (Utrecht, the Netherlands), P. Bresser (Amsterdam, the Netherlands), H. Gooszen and J. Creemers (Eindhoven, the Netherlands), R. Avila (Lisboa, Portugal), R. de Almeida (Vila Nova de Gaia, Portugal), L. Oliveira (Coimbra, Portugal), I. Gomes (Porto, Portugal), D. Nowak (Lodz, Poland), J. Zielinski (Warsaw, Poland), G. Riise (Gothenburg, Sweden).

\section{References}

1. Siafakas NM, Vermeire P, Pride NB, et al. Optimal assessment and management of COPD. Eur Respir $J$ 1995; 8: $1398-1420$.

2. Jeffery P. Inflammation in COPD. Am J Respir Crit Care Med 1999; 160: S3-S4.

3. Barnes PJ. Chronic Obstructive Pulmonary Disease. $N$ Eng J Med 2000; 343: 269-280.

4. Barnes P. Novel approaches and targets for the treatment of COPD. Am J Respir Crit Care Med 1999; 160: S72 - S79.

5. Pauwels RA, Löfdahl CG, Laitinen LA, et al. Longterm treatment with inhaled budesonide in persons with mild COPD who continue smoking. N Eng J Med 1999; 340: 1948 - 1953

6. Vestbo J, Sørensen T, Lange P, Brix A, Torre P, Viskum K. Long-term effect of inhaled budesonide in mild and moderate chronic obstructive pulmonary disease: a randomised controlled trial. Lancet 1999; 353: $1819-1823$.

7. Burge PS, Calverley PMA, Jones PW, Spencer P, Anderson JA, Maslen TK. Randomised, double blind, placebo controlled study of fluticasone propionate in patients with moderate to severe chronic obstructive pulmonary disease: the ISOLDE trial. $B M J 2000 ; 320$ : $1297-1303$.

8. Anthonisen NR, Connett JE, Kiley JP, et al. Effects of smoking intervention and the use of anticholinergic bronchodilator on the rate of decline of FEV1. The lung health study. JAMA 1994; 272: 1497-1505.

9. Postma DS, Peters SI, Steenhuis EJ, Sluiter HJ. Moderately severe chronic airflow obstruction: can steroids slow down obstruction? Eur Respir J 1988; 1: $22-26$.

10. Ström KJ. Survival of patients with COPD receiving long-term domiciliary oxygen therapy. Am J Respir Crit Care Med 1993; 147: 585-591.

11. Boman $\mathrm{G}$, Bäcker $\mathrm{U}$, Larsson $\mathrm{S}$, Melander $\mathrm{B}$, 
Wählander L. Oral acetylcysteine reduces exacerbation rate in chronic bronchitis: report of a trial organised by the Swedish Society for Pulmonary diseases. Eur J Respir Dis 1983; 64: 405-415.

12. Multicentre Study Group. Long-term oral acetylcysteine in chronic bronchitis. A double-blind controlled study. Eur J Respir Dis 1980; 61: Suppl 111. 93-108.

13. Rasmussen JB, Gleenow C. Reduction in days of illness after long-term treatment with $\mathrm{N}$-acetylcysteine controlled-release tablets in patients with chronic bronchitis. Eur Respir J 1988; 1: 351-355.

14. McGavin CR, the British Thoracic Society Research Committee. Oral $\mathrm{N}$-acetylcysteine and exacerbation rates in patients with chronic bronchitis and severe airways obstruction. Thorax 1985; 40: 823-835.

15. Grandjean EM, Berthet P, Ruffman R, Leuenberger P. Efficacy of oral long-term $\mathrm{N}$-acetylcysteine in chronic bronchopulmonary disease: a meta-analysis of published double-blind, placebo-controlled clinical trials. Clin Ther 2000; 22: 209-221.

16. Stey C, Steurer J, Bachmann S, Medici TC, Tramer MR. The effects of oral $\mathrm{N}$-acetylcysteine in chronic bronchitis: a quantitative systematic review. Eur Respir J 2000; 16: 253-262.

17. Repine JE, Bast A, Lankhorst I and the Oxidative Stress Study Group. Oxidative stress in COPD. Am J Respir Crit Care Med 1997; 156: 341 - 357.

18. MacNee W, Rahman I. Oxidants and antioxidants as therapeutic targets in COPD. Am J Respir Crit Care Med 1999; 160: S58-S65.

19. van den Boom G, Donkers JM, Tirimanna PRS, et al. Measuring individual annual decline in lung function: the impact of measurement frequency and precision. $J$ Clin Epid (in press).

20. Quanjer Ph. Standardized lung function testing. Eur Respir J 1993; 6: Suppl 16, 5-40.

21. Enright PL, Connett JE, Kanner RE, Johnson LR,
Lee WW for the Lung Health Study Group. Spirometry in the Lung Health Study II: Determinants of short-term intraindividual varaibility. Am J Respir Crit Care Med 1995; 151: 406-411.

22. Jones PW, Quirk F, Baveystock CM, Littlejohns P. A self-complete measure of health status for chronic airflow limitation. The St. George's Respiratory Questionnaire. Am Rev Respir Dis 1992; 145: $1321-$ 1327.

23. Quirk FH, Baveystock CM, Wilson RC, Jones PW. Influence of demographic and disease related factorson the degree of distress associated with symptoms and restriction on daily diving due to asthma in six countries. Eur Respir J 1991; 4: $167-171$.

24. Broocks R with the EuroQol Group. EuroQoL: the current state of the play. Health policy 1996; 37: $53-72$.

25. Doolan P. Modeling valuations for EuroQol health states. Medicare 1997; 35: $1095-1109$.

26. Koopmanschap MA, Rutten FFH, Van Ineveld BM, Roijen L. The friction cost method for measuring indirect costs of disease. J Health Econ 1995; 14: 171 189.

27. Van den Boom G, van Schayck CP, Rutten-van Mölken MPMH, et al. Active detection of chronic obstructive pulmonary disease and asthma in the general population. Am J Respir Crit Care Med 1998; 158: $1730-1738$

28. Dirksen A, Holstein-Rathlon NH, Madsen F, et al. Long-range correlations of serial FEV1 measurements in emphysematous patients and normal subjects. $J$ Appl Physiol 1998; 85: 259-265.

29. Seemungal TA, Donaldson GC, Bhowmik A, Jeffries DJ, Wedzicha JA. Time course and recovery of exacerbations in patients with obstructive pulmonary disease. Am J Respir Crit Care Med 2000; 161: $1608-1613$. 